\title{
Pharmacokinetics and safety of a single intravenous dose of myo-inositol in preterm infants of 23-29 wk
}

Dale L. Phelps ${ }^{1}$, Robert M. Ward², Rick L. Williams ${ }^{3}$, Kristi L. Watterberg ${ }^{4}$, Abbot R. Laptook ${ }^{5}$, Lisa A. Wrage ${ }^{3}$, Tracy L. Nolen ${ }^{3}$, Timothy R. Fennell ${ }^{6}$, Richard A. Ehrenkranz ${ }^{7}$, Brenda B. Poindexter ${ }^{8}$, C. Michael Cotten ${ }^{9}$, Mikko K. Hallmann ${ }^{10,11}$, Ivan D. Frantz III'12, Roger G. Faix ${ }^{2}$, Kristin M. Zaterka-Baxter ${ }^{3}$, Abhik Das ${ }^{13}$, M. Bethany Ball14 ${ }^{14}$, T. Michael O'Shea ${ }^{15}$, Conra Backstrom Lacy ${ }^{4}$, Michele C. Walsh ${ }^{16}$, Seetha Shankaran ${ }^{17}$, Pablo J. Sánchez ${ }^{18}$, Edward F. Bell ${ }^{19}$ and Rosemary D. Higgins ${ }^{20}$; for the Eunice Kennedy Shriver National Institute of Child Health and Human Development Neonatal Research Network

BACKGROUND: Myo-inositol given to preterm infants with respiratory distress has reduced death, increased survival without bronchopulmonary dysplasia, and reduced severe retinopathy of prematurity in two randomized trials. Pharmacokinetic (PK) studies in extremely preterm infants are needed before efficacy trials.

METHODS: Infants born in 23-29wk of gestation were randomized to a single intravenous (i.v.) dose of inositol at 60 or $120 \mathrm{mg} / \mathrm{kg}$ or placebo. Over $96 \mathrm{~h}$, serum levels (sparse sampling population PK) and urine inositol excretion were determined. Population PK models were fit using a nonlinear mixed-effects approach. Safety outcomes were recorded.

RESULTS: A single-compartment model that included factors for endogenous inositol production, allometric size based on weight, gestational age strata, and creatinine clearance fit the data best. The central volume of distribution was 0.5115 $1 / \mathrm{kg}$, the clearance was $0.0679 \mathrm{l} / \mathrm{kg} / \mathrm{h}$, endogenous production was $2.67 \mathrm{mg} / \mathrm{kg} / \mathrm{h}$, and the half-life was $5.22 \mathrm{~h}$ when modeled without the covariates. During the first $12 \mathrm{~h}$, renal inositol excretion quadrupled in the $120 \mathrm{mg} / \mathrm{kg}$ group, returning to near-baseline value after $48 \mathrm{~h}$. There was no diuretic side effect. No significant differences in adverse events occurred among the three groups $(P>0.05)$.

CONCLUSION: A single-compartment model accounting for endogenous production satisfactorily described the PK of i.v. inositol.

nositol is ubiquitous in living organisms where it is largely present as a free sugar alcohol and also as a head group of membrane lipids. In addition, phosphoinositides and glycosylphoshatidylinositols have specific roles in signal transduction and in lipid-protein interactions (1-4). In its free form, inositol is a sugar alcohol present in human milk, widely available in the diet, and it has been classified as "generally regarded as safe" for enteral administration by the US Food and Drug Administration. In utero, early fetal serum inositol levels are 2-10 times higher than adult levels and decrease gradually toward term (5-7). Inositol has been supplemented in infant formulas since the late $1990 \mathrm{~s}$ at $\sim 44 \mathrm{mg} / 100 \mathrm{kcal}(350 \mathrm{mg} / \mathrm{l})$, yet its clearance has not been studied in extremely preterm newborns. If an infant is not receiving enteral milk feedings, serum levels substantially decrease below the in utero levels at a comparable age. $(5,6)$.

Hallman et al. (8-11) administered myo-inositol intravenously (i.v.) and/or enterally to preterm infants with respiratory distress syndrome in two randomized trials and found increased survival, increased survival without bronchopulmonary dysplasia, reduced severe retinopathy of prematurity, reduced severe intraventricular hemorrhage (IVH), and no observed toxicity. An additional partially randomized trial of inositol-supplemented formula in preterm infants (12) was also considered in the Cochrane review of inositol. The review concluded the combined findings warrant further study, particularly in the extremely preterm infants who remain at highest risk for these morbidities (13).

The endogenous production and metabolism of inositol, combined with dietary intake, add complexity to a pharmacokinetic (PK) analysis. However, to inform dosing of i.v. inositol

\footnotetext{
'The School of Medicine and Dentistry, University of Rochester, Rochester, New York; ${ }^{2}$ Department of Pediatrics, Division of Neonatology, School of Medicine, University of Utah, Salt Lake City, Utah; ${ }^{3}$ Statistics and Epidemiology Unit, RTI International, Research Triangle Park, North Carolina; ${ }^{4}$ University of New Mexico Health Sciences Center, Albuquerque, New Mexico; ${ }^{5}$ Department of Pediatrics, Women and Infants Hospital, Brown University, Providence, Rhode Island; ${ }^{6}$ Pharmacology and Toxicology Division, RTI International, Research Triangle Park, North Carolina; ${ }^{7}$ Department of Pediatrics, Yale University School of Medicine, New Haven, Connecticut; ${ }^{8}$ Department of Pediatrics, Indiana University School of Medicine, Indianapolis, Indiana; ${ }^{9}$ Department of Pediatrics, Duke University, Durham, North Carolina; ${ }^{10}$ Department of Pediatrics, University of Oulu, Oulu, Finland; ${ }^{11}$ Oulu University Hospital, Oulu, Finland; ${ }^{12}$ Division of Newborn Medicine, Department of Pediatrics, Floating Hospital for Children, Tufts Medical Center, Boston, Massachusetts; ${ }^{13}$ Statistics and Epidemiology Unit, RTI International, Rockville, Maryland; ${ }^{14}$ Division of Neonatal and Developmental Medicine, Department of Pediatrics, Lucile Packard Children's Hospital, Stanford University School of Medicine, Palo Alto, California; ${ }^{15}$ Wake Forest University School of Medicine, Winston-Salem, North Carolina; ${ }^{16}$ Department of Pediatrics, Rainbow Babies and Children's Hospital, Case Western Reserve University, Cleveland, Ohio; ${ }^{17}$ Department of Pediatrics, Wayne State University, Detroit, Michigan; ${ }^{18}$ Department of Pediatrics, University of Texas Southwestern Medical Center, Dallas, Texas; ${ }^{19}$ Department of Pediatrics, University of lowa, lowa City, lowa; ${ }^{20}$ Eunice Kennedy Shriver National Institute of Child Health and Human Development, National Institutes of Health, Bethesda, Maryland. Correspondence: Dale L. Phelps (dale_phelps@urmc.rochester.edu)
} 
in extremely preterm infants, we need to improve our understanding of its disposition in this population.

\section{RESULTS}

\section{Population Demographics}

Figure 1 shows the flow chart of screened, randomized, and analyzed infants between June 2006 and December 2007 at 10 participating centers. Consent was obtained for 79 infants, 76 infants were randomized, and 74 infants received study drug. Two infants did not complete the minimum of four specified blood samples (three postdrug infusion), and their randomizations were replaced with two additional enrollees from the same center and of the same gestational age (GA) stratum, per protocol. Available data from the two replaced infants were included in the PK and safety analyses. One infant received placebo instead of the assigned $120 \mathrm{mg} / \mathrm{kg}$ dose, and for the PK analysis, this infant's serum and urine data were included in the placebo group. However, this subject's data on adverse events and clinical outcomes were included as randomized (intention to treat). The baseline characteristics of the randomized infants were similar across all three groups. The median age at the time of study drug infusion was between 2.4 and $3.2 \mathrm{~d}$ (Table 1).

\section{Safety}

During the infusions, heart rate, blood pressure, and respiration did not differ between placebo and inositol infants at either dose (data not shown). The incidence of at least one adverse event was lowest for the higher dose of inositol: $80 \%$ in the placebo, $84 \%$ in the $60 \mathrm{mg} / \mathrm{kg}$, and $54 \%$ in the $120 \mathrm{mg} / \mathrm{kg}$ group $(P=0.05$; Table 2). The frequencies of sepsis, IVH, need for supplemental oxygen, need for mechanical ventilation, and use of the specified medications did not differ significantly among the groups, nor did early specified clinical diagnoses during the first $4 \mathrm{~d}$ after infusion (Table 2). Serious adverse events occurred in 29\%

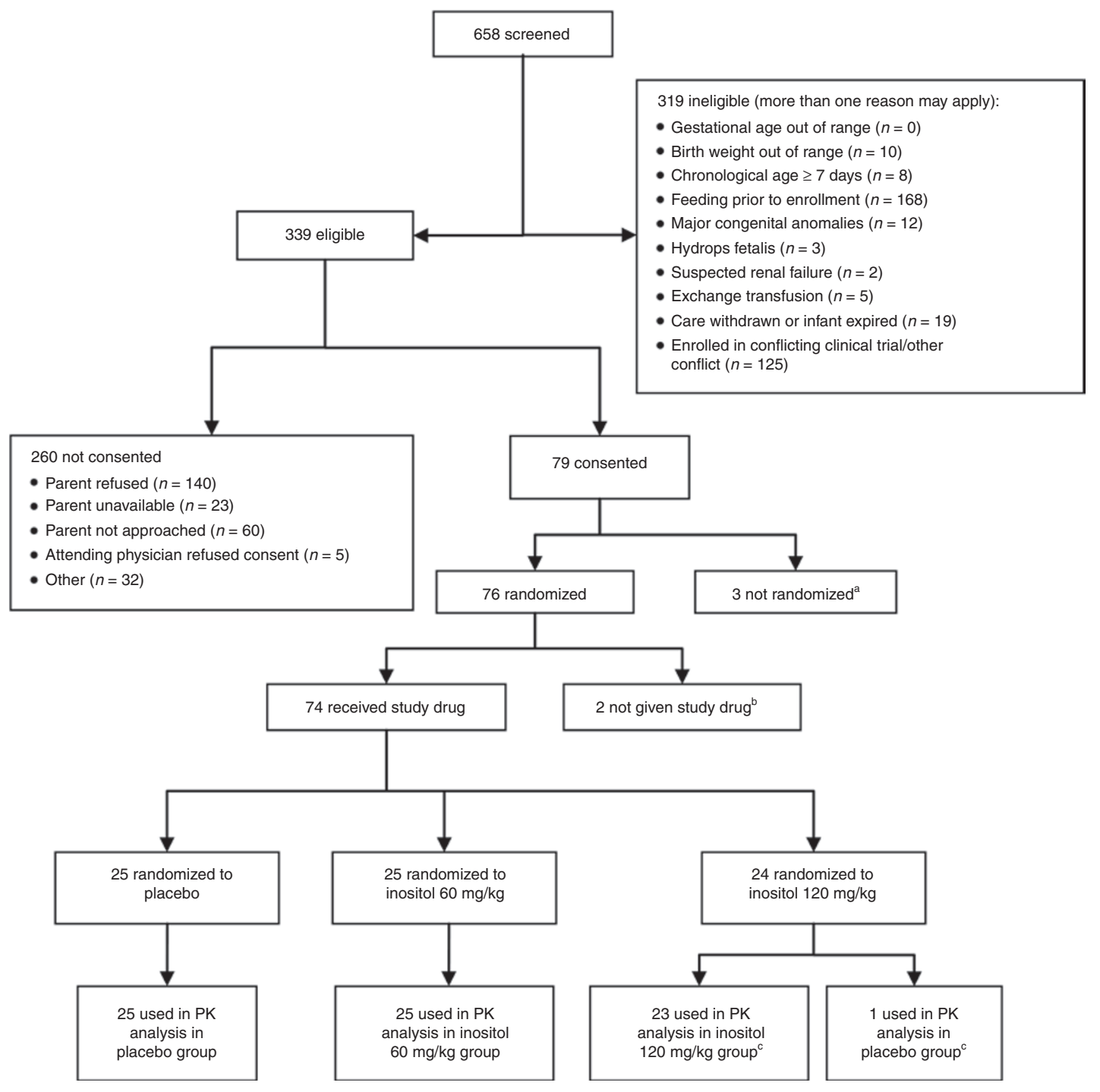

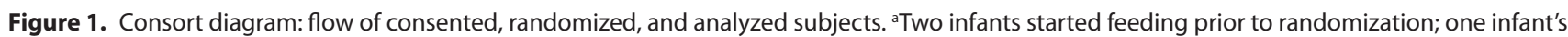

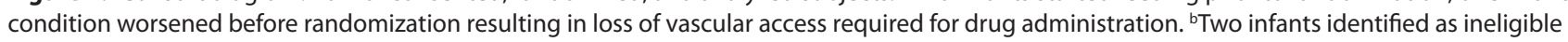
postrandomization (one had $<600 \mathrm{~g}$ birth weight, one developed severe intraventricular hemorrhage postconsent). 'One infant received placebo in error, samples included as placebo in the pharmacokinetic (PK) analyses; however, clinical outcomes included as intention to treat. 
Table 1. Baseline characteristics of randomized infants by treatment group

\begin{tabular}{|c|c|c|c|c|c|}
\hline Characteristic & & Placebo $(n=25)$ & Inositol $60 \mathrm{mg} / \mathrm{kg}(n=25)$ & Inositol $120 \mathrm{mg} / \mathrm{kg}(n=24)$ & $P$ value \\
\hline Gestational age (wk) & Median (range) & $26.9(24.0-29.3)$ & $26.7(23.7-29.7)$ & $27.1(23.7-29.7)$ & 0.98 \\
\hline Gestational age stratum & $27-29 \mathrm{wk}, n(\%)$ & $12(48 \%)$ & $12(48 \%)$ & $13(54 \%)$ & 0.88 \\
\hline Gender & Female, $n(\%)$ & $12(48 \%)$ & $14(56 \%)$ & $11(46 \%)$ & 0.75 \\
\hline Race, non-Hispanic white & $n(\%)$ & $11(44 \%)$ & $12(48 \%)$ & $12(50 \%)$ & 0.91 \\
\hline Chorioamnionitis & $n$ (\% yes) & $8(32 \%)$ & $5(20 \%)$ & $5(21 \%)$ & 0.54 \\
\hline Apgar score, 1 min $^{\mathrm{a}}$ & Median (range) & $4.5(1-9)$ & $6.5(0-9)$ & $6(1-9)$ & 0.51 \\
\hline Apgar score, 5 min $^{\mathrm{a}}$ & Median (range) & $7(4-9)$ & $7(0-9)$ & $8(1-9)$ & 0.47 \\
\hline Age (days) at infusion & Median (range) & $3.2(1.4-5.2)$ & $3.1(1.4-5.1)$ & $2.4(1.4-4.9)$ & 0.22 \\
\hline
\end{tabular}

aMissing Apgar scores: infant born in ambulance $(n=1)$; infant born in Mexico $(n=1)$.

Table 2. Clinical outcomes through day 7 after infusion by treatment group

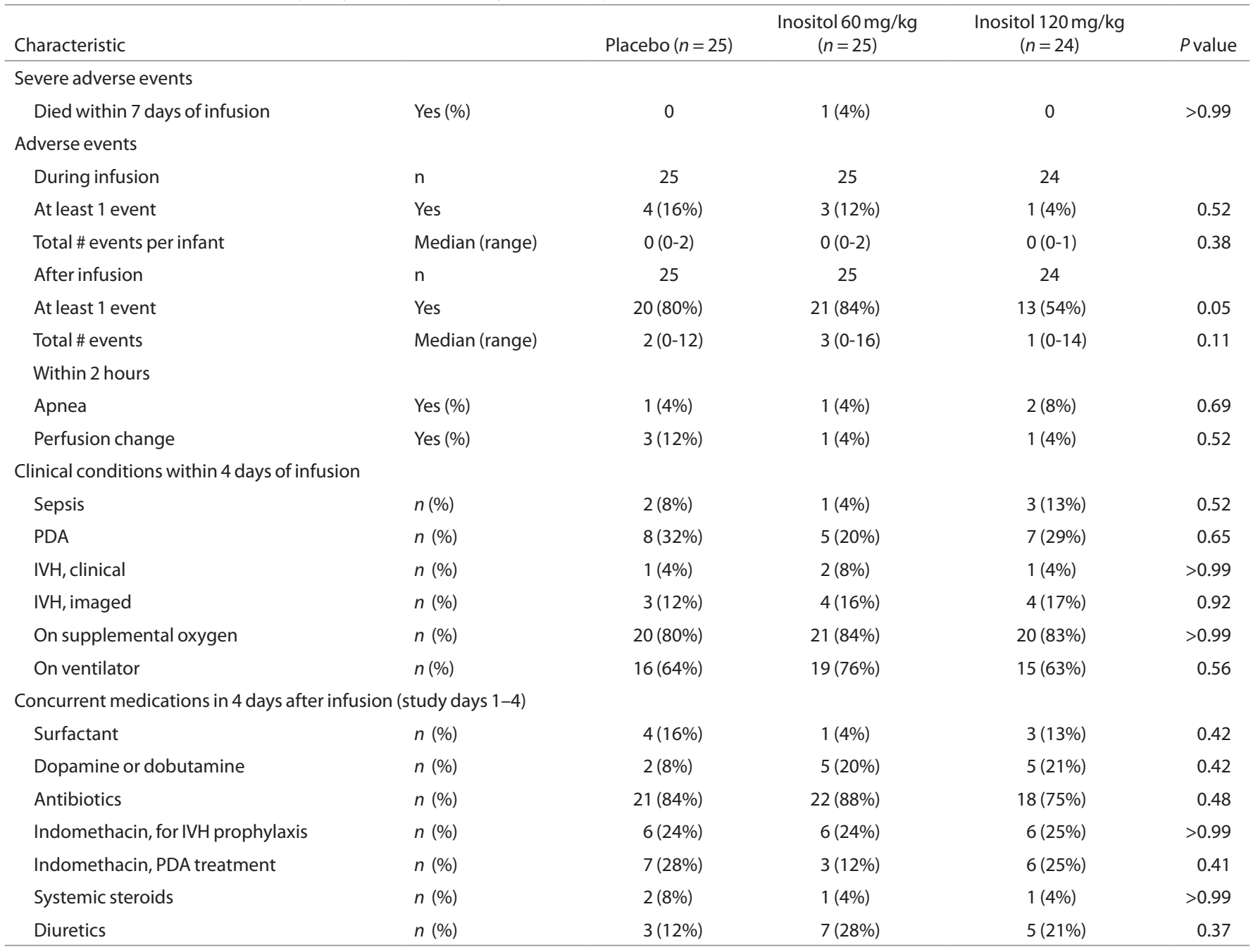

PDA, patent ductus arteriosus; IVH, intraventricular hemorrhage.

of all subjects and were lowest in the $120 \mathrm{mg} / \mathrm{kg}$ group (17\%; $P=0.11)$ (data not shown, tables available from the authors). During hospitalization, there were no significant differences between groups in the rates of expected preterm diagnoses as a whole (Table 3), nor between groups in the upper or lower GA strata. Clinical event rates were similar to historic data observed in this population in the National Institutes of Child Health and Human Development Neonatal Research Network (14). 
Articles | Phelpset al.

Table 3. Clinical outcomes and adverse events by treatment group

\begin{tabular}{|c|c|c|c|c|c|}
\hline Characteristic $^{\mathrm{a}}$ & & Placebo $(n=25)$ & Inositol $60 \mathrm{mg} / \mathrm{kg}(n=25)$ & Inositol $120 \mathrm{mg} / \mathrm{kg}(n=24)$ & $P$ value \\
\hline \multirow[t]{2}{*}{ Died before discharge } & $n$ & 25 & 25 & 24 & $>0.99$ \\
\hline & Yes (\%) & $3(12 \%)$ & $4(16 \%)$ & $3(12 \%)$ & \\
\hline \multirow[t]{2}{*}{$\mathrm{BPD}$ (on $\mathrm{O}_{2}$ at 36 wk PMA) } & $n$ & 23 & 21 & 21 & 0.09 \\
\hline & Yes (\%) & $3(13 \%)$ & $6(29 \%)$ & $9(43 \%)$ & \\
\hline \multirow[t]{2}{*}{ Days on oxygen } & $n$ & 25 & 25 & 24 & 0.22 \\
\hline & Median (range) & $32(1-108)$ & $32(1-120)$ & $53(0-120)$ & \\
\hline \multirow[t]{2}{*}{ PDA } & $n$ & 25 & 25 & 24 & 0.20 \\
\hline & Yes (\%) & $13(52 \%)$ & $7(28 \%)$ & $11(46 \%)$ & \\
\hline \multirow[t]{2}{*}{ If PDA, indomethacin Rx } & $n$ & 13 & 7 & 11 & 0.36 \\
\hline & Yes (\%) & $7(54 \%)$ & $4(57 \%)$ & $9(82 \%)$ & \\
\hline \multirow[t]{2}{*}{ If PDA, surgical ligation } & $n$ & 13 & 7 & 11 & 0.35 \\
\hline & Yes (\%) & $2(15 \%)$ & $3(43 \%)$ & $4(36 \%)$ & \\
\hline \multirow[t]{2}{*}{ IVH grade 3 or 4} & $n$ & 25 & 24 & 23 & 0.22 \\
\hline & Yes (\%) & $3(12 \%)$ & $5(21 \%)$ & $1(4 \%)$ & \\
\hline \multirow[t]{2}{*}{ Seizures treated $>72 \mathrm{~h}$} & $n$ & 25 & 25 & 24 & 0.31 \\
\hline & Yes (\%) & 0 & $1(4 \%)$ & $2(8 \%)$ & \\
\hline \multirow[t]{2}{*}{ Sepsis, late onset } & $n$ & 25 & 25 & 24 & 0.09 \\
\hline & Yes (\%) & $7(28 \%)$ & $7(28 \%)$ & $13(54 \%)$ & \\
\hline \multirow[t]{2}{*}{ NEC IIA or worse } & $n$ & 25 & 25 & 24 & 0.49 \\
\hline & Yes (\%) & $5(20 \%)$ & $2(8 \%)$ & $2(8 \%)$ & \\
\hline \multirow[t]{2}{*}{ If NEC, had surgery } & $n$ & 5 & 2 & 2 & $>0.99$ \\
\hline & Yes (\%) & $2(40 \%)$ & $1(50 \%)$ & $1(50 \%)$ & \\
\hline \multirow{2}{*}{$\begin{array}{l}\text { Spontaneous gastrointestinal } \\
\text { perforation, no NEC }\end{array}$} & $n$ & 25 & 25 & 24 & 0.32 \\
\hline & Yes (\%) & 0 & $2(8 \%)$ & 0 & \\
\hline \multirow[t]{2}{*}{ Hearing test, failed both ears } & $n$ & 21 & 17 & 19 & 0.77 \\
\hline & Yes (\%) & $2(10 \%)$ & 0 & $1(5 \%)$ & \\
\hline \multirow[t]{2}{*}{ ROP } & $\begin{array}{l}\text { Final status } \\
\text { known }\end{array}$ & 8 & 8 & 9 & 0.21 \\
\hline & $\begin{array}{l}\text { Received surgery } \\
\text { for ROP (\%) }\end{array}$ & $4(50 \%)$ & $2(25 \%)$ & $1(11 \%)$ & \\
\hline
\end{tabular}

BPD, bronchopulmonary dysplasia; IVH, intraventricular hemorrhage; NEC, necrotizing enterocolitis; PDA, patent ductus arteriosus; PMA, postmenstrual age (=gestational age + chronologic age); ROP, retinopathy of prematurity.

aNumber of subjects in the denominator shown because of variation.

\section{PK Analyses}

The raw mean serum levels rose in proportion to the dose given, gradually returned to baseline (Figure 2), and appeared consistent with the compartmental model under consideration.

The PK analysis, which included endogenous production, revealed no improvement between one- and two-compartment models $(P=0.38)$, so a one-compartment model was used. In the measurement of residual error, a constant variance best fit the data. The relationships between the random effects were graphically studied by plotting $u_{v i}$ vs. $u_{C l i}, u_{V i}$ vs. $u_{R i}$, and $u_{C l i}$ vs. $u_{R i}$ for all infants (see Methods section for formulas and definitions). A strong linear relationship was observed between the random-effect estimates for clearance $(\mathrm{Cl})$ and endogenous production $(R)$ with no apparent relationship between the other two combinations of random effects. The random effects were then modeled only with correlation between $C l$ and $R$.
Table 4 presents the population-PK (Pop-PK) estimates for the one-compartment model excluding any covariates with the associated random-effect variance and correlation estimates in Table 5. Derived values for the elimination rate, the half-life, and the apparent concentration associated with endogenous production are also shown in Table 4. The model appears to provide a good fit to the data as shown in Figure 3 with the observed and individual predicted values being well aligned. The mass of data points at the low values are primarily comprised of predosing and placebo measurements combined with a smaller number of late time point measurements, all of which are expected to have low inositol concentrations. Residual plots comparing predicted and actual values, not included here, did not indicate any major model deficiencies.

This model was used to assist the investigators to project the effect on serum levels of inositol from repeated dosing 


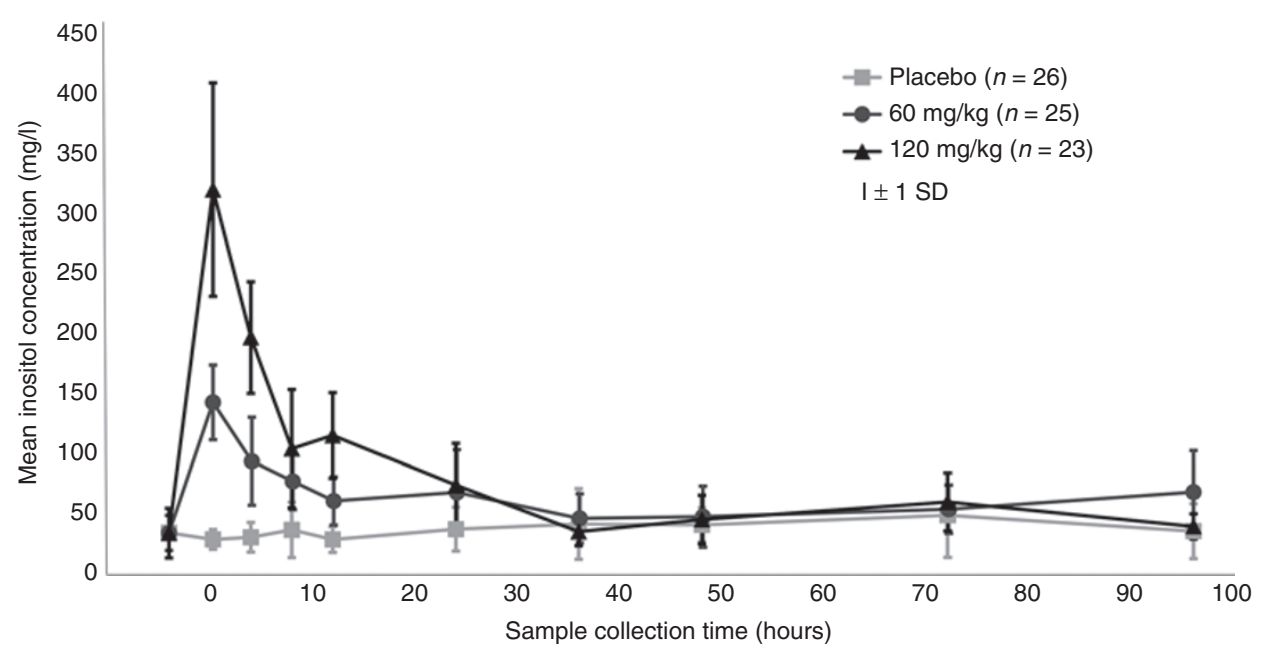

Figure 2. Serum inositol levels by dose group. Samples were collected within scheduled windows, plus additional scavenged samples as available. For this graph, collection times were clustered as follows to obtain mean values: $0 \mathrm{~h}$ (baseline) $=$ obtained before infusion; $0.3 \mathrm{~h}$ (end of infusion) $=0-2-\mathrm{h}$ postinfusion; $4 \mathrm{~h}=2-6-\mathrm{h}$ postinfusion; $8 \mathrm{~h}=6-10-\mathrm{h}$ postinfusion; $12 \mathrm{~h}=10-14-\mathrm{h}$ postinfusion; $24 \mathrm{~h}=14-30-\mathrm{h}$ postinfusion; $36 \mathrm{~h}=30-42-\mathrm{h}$ postinfusion; $48 \mathrm{~h}=42-60-\mathrm{h}$ postinfusion; $72 \mathrm{~h}=60-82-\mathrm{h}$ postinfusion; $96 \mathrm{~h}=>82-\mathrm{h}$ postinfusion. Light gray squares, placebo; gray circles, $60 \mathrm{mg} / \mathrm{kg} ; \mathrm{black}$ triangles, $120 \mathrm{mg} / \mathrm{kg}$; vertical bar, \pm 1 SD.

Table 4. Population pharmacokinetic parameter estimates for a typical infant (fixed effects)

\begin{tabular}{llll}
\hline Parameter & Units & Estimate & SE \\
\hline Model parameters & & & \\
$\quad V$ (volume) & $\mathrm{l} / \mathrm{kg}$ & 0.5115 & 0.0345 \\
$C l$ (clearance) & $\mathrm{l} / \mathrm{kg} / \mathrm{h}$ & 0.0679 & 0.0064 \\
$\quad R$ (endogenous infusion rate) & $\mathrm{mg} / \mathrm{kg} / \mathrm{h}$ & 2.666 & 0.2762 \\
$\quad$ SD of the residual error & $\mathrm{mg} / \mathrm{l}$ & 18.71 & 1.048 \\
Derived values & & & \\
$\quad k$ (elimination rate; $C / M$ & $1 / \mathrm{h}$ & 0.133 & 0.0154 \\
$t_{1 / 2}$ (half-life; $0.693 / k$ ) & $\mathrm{h}$ & 5.22 & 0.605 \\
$E$ (endogenous concentration; $R / C l)$ & $\mathrm{mg} / \mathrm{l}$ & 39.25 & 1.655 \\
\hline
\end{tabular}

Table 5. Population pharmacokinetic random effects variances and correlations

\begin{tabular}{lccc}
\hline & Volume $\left(u_{v}\right)$ & Clearance $\left(u_{C l}\right)$ & $\begin{array}{c}\text { Endogenous } \\
\text { infusion rate }\left(u_{R}\right)\end{array}$ \\
\hline Volume $\left(u_{v}\right)$ & 0.08506 & - & - \\
Clearance $\left(u_{C l}\right)$ & $0.0^{\mathrm{a}}$ & 0.22636 & - \\
Endogenous & $0.0^{\mathrm{a}}$ & 0.87606 & 0.14492 \\
infusion rate $\left(u_{R}\right)$ & & & \\
\hline
\end{tabular}

Random effect variances on the diagonal and correlations between the random effects are displayed on the off diagonal.

aCorrelation set to 0.0 (zero) based on review of plots of $u_{v i} v s . u_{C i j}$ and $u_{v i} v s . u_{R i}$

with every 12 -h or every 24 -h schedules using several different daily doses. As an example, Figure 4 shows the model's prediction for $80 \mathrm{mg} / \mathrm{kg} / \mathrm{d}$ divided into two doses every $12 \mathrm{~h}$, for $36 \mathrm{~h}$. Although this study did not directly evaluate multiple dose administrations, the model's estimate represents probable serum levels over a short time period for planning future studies of repeated administration.

The effect of the following covariates on each of the model parameters was tested: infant birth weight, allometric size at birth, GA strata at birth (23-26 vs. $27-29$ weeks), postmenstrual age, postnatal age, creatinine clearance, and sex (15). Allometric size, a function of birth weight, entered the model for a parameter as a multiplicative scaling factor given by $F_{\text {size }}=\left(w_{i} / \widetilde{w}\right)^{\beta_{\text {size }}}$, where $w_{i}$ is the birth weight, in grams, for the $i$ th infant, $\widetilde{w}$ is the median birth weight of the infants in the study (997.5 g), and $\beta_{\text {size }}$ is the estimated coefficient. The remaining covariates had an exponential multiplicative effect given by $F_{z}=e^{\beta_{z} \times z}$ where $z$ is one of the covariates. Table 6 presents the mean and SDs for the continuous covariates while the two categorical covariates were both equally divided with $50 \%$ in each of their two categories.

Each covariate was tested individually against the base model. Those covariates found to have a statistically significant effect on any of the three Pop-PK model parameters, $R, C l$, and $V(V$ $=$ volume of distribution), were then combined into a single model. Birth weight, postmenstrual age, postnatal age, and sex had no significant effects on the model parameters. Allometric size, GA strata, and creatinine clearance were found to have a statistically significant effect on one or more of the three model parameters (Table 7). The final model including all of the statistically significant covariates indicates that infants with a GA of 27-29wk had a lower volume of distribution than infants with a lower GA of $23-26 \mathrm{wk}$, while clearance increased with increasing allometric size. The pathway of influence for creatinine clearance was less clear. When its effect was considered separately on each of the model parameters, $\mathrm{V}, \mathrm{Cl}$, and $\mathrm{R}$, it was statistically significant for $C l$ and $R(P=0.044$ and $P=0.014$, respectively) with a direction of effect that was physiologically plausible, increasing for $\mathrm{Cl}$ and decreasing for $\mathrm{R}$. However, when creatinine clearance was allowed to simultaneously affect both $\mathrm{Cl}$ and $\mathrm{R}$, then its direction of effect on $\mathrm{Cl}$ was the opposite of that expected with increased creatinine clearance leading to a reduction in $\mathrm{Cl}$. In addition, the model with creatinine clearance affecting $R$ alone was not significantly different from the 


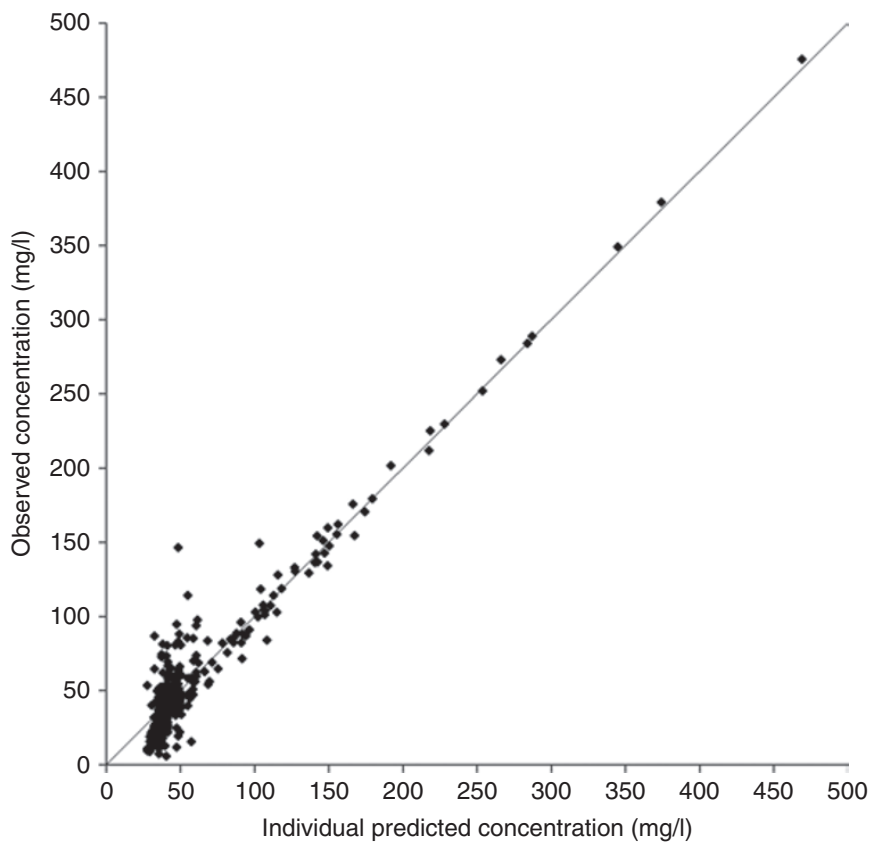

Figure 3. Observed vs. individual predicted inositol concentrations from the population pharmacokinetic analysis. Predicted values were calculated for each observed data point using the individual characteristics in the model described in the PK section of the Results section.

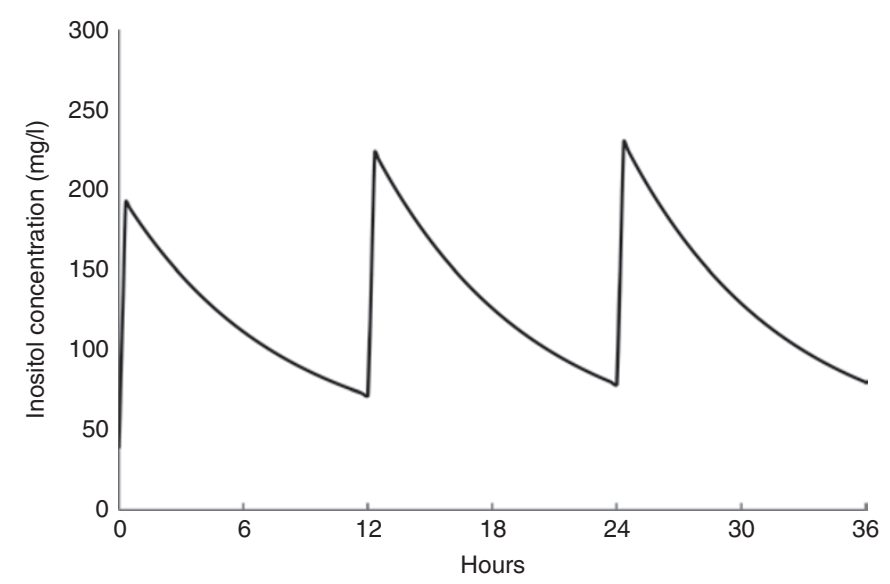

Figure 4. Predicted serum inositol model. The model described in the PK results section (before covariates) was used to predict the pattern of serum levels for a typical infant given repeated doses of $80 \mathrm{mg} / \mathrm{kg} / \mathrm{d}$ divided into $40 \mathrm{mg} / \mathrm{kg}$ every $12 \mathrm{~h}$ for $36 \mathrm{~h}$.

model with creatinine clearance affecting both $C l$ and $R(P=$ 0.29). Therefore, the final covariate model included the effect of creatinine clearance solely on $R$. The estimated typical value for each of the three model parameters were affected as follows by the final covariate model:

$$
\begin{aligned}
V^{*} & =0.5924 \times \exp [-0.2777 \times I(\mathrm{GA})] \\
C l^{*} & =0.0549 \times\left(\frac{\text { Birth weight }}{997.5}\right)^{0.2158} \\
R^{*} & =3.040 \times \exp [-0.1898 \times \mathrm{CrCl}]
\end{aligned}
$$

Table 6. Covariate means and SDs

\begin{tabular}{lcc}
\hline Covariate & Mean & SD \\
\hline Birth weight $(\mathrm{g})$ & 986.8 & 245.0 \\
Size at birth $\left(w_{i} / \widetilde{w}\right)$ & 0.989 & 0.246 \\
Postmenstrual age $(\mathrm{wk})$ & 27.3 & 1.72 \\
Postnatal age $(\mathrm{wk})$ & 0.44 & 1.15 \\
Creatinine clearance $(\mathrm{ml} / \mathrm{min})$ & 0.69 & 0.34 \\
\hline
\end{tabular}

where $V^{*}, \mathrm{Cl}^{*}$, and $\mathrm{R}^{*}$ are the covariate-adjusted model parameters and $I(\mathrm{GA})$ is an indicator function that equals 0 (zero) for GA stratum 23-26 wk and 1 for stratum 27-29wk.

\section{Urine Excretion of Inositol}

Excretion in the placebo infants had a baseline rate of $26.6 \pm 12.3 \mathrm{mg} / \mathrm{kg} / 24 \mathrm{~h}$ (mean $\pm \mathrm{SD}$ ) and showed an upward trend with age over the $96-\mathrm{h}$ study to $36.8 \pm 28.8 \mathrm{mg} / \mathrm{kg} / 24 \mathrm{~h}$ on day 4 of the study. Following inositol administration, excretion rose during the first 12-h collection and decreased in the second $12 \mathrm{~h}$. Thereafter, excretion approached levels in the placebo group. Following the $120 \mathrm{mg} / \mathrm{kg}$ dose, average excretion was $67.3 \pm 35.8 \mathrm{mg} / \mathrm{kg}$ in the first $12 \mathrm{~h}$ and $25.3 \pm 14.4 \mathrm{mg} / \mathrm{kg}$ in the second $12 \mathrm{~h}$. For the $60 \mathrm{mg} / \mathrm{kg}$ subjects, $31.9 \pm 13.4 \mathrm{mg} / \mathrm{kg}$ was excreted in the first $12 \mathrm{~h}$ and $18.0 \pm 9.6 \mathrm{mg} / \mathrm{kg}$ in the second $12 \mathrm{~h}$.

We examined the volume of urine output for evidence of a potential diuretic effect of the excreted inositol and found none. The mean volume of urine in the first $12 \mathrm{~h}$ after drug dosing when excretion was the highest was $40.7 \mathrm{ml} / \mathrm{kg} / 12 \mathrm{~h}$ in placebo infants, $37.8 \mathrm{ml} / \mathrm{kg} / 12 \mathrm{~h}$ in the $60 \mathrm{mg} / \mathrm{kg}$ group, and $46.2 \mathrm{ml} / \mathrm{kg} / 12 \mathrm{~h}$ in the $120 \mathrm{mg} / \mathrm{kg}$ group, respectively $(P$ value $=$ 0.1242; Kruskal-Wallis test).

\section{DISCUSSION}

These findings demonstrate that among preterm infants of 23-29 weeks gestation, a single i.v. dose of $60 \mathrm{mg} / \mathrm{kg}$ or $120 \mathrm{mg} /$ $\mathrm{kg}$ inositol given over $20 \mathrm{~min}$ results in an initial dose proportional increase in serum concentrations that persists between 24 and $36 \mathrm{~h}$. Accommodating a parameter for endogenous production, the PK analysis showed a central volume of distribution of $0.5115 \mathrm{l} / \mathrm{kg}$ with a half-life of $5.22 \mathrm{~h}$ when excluding any covariate effects. Although increased urine inositol loss occurred initially, this did not result in a diuresis.

Previous controlled trials suggest that supplemental inositol is safe and beneficial for preterm infants. The serum level achieved in the key study demonstrating a good benefit was $126-153 \mathrm{mg} / \mathrm{l}$ during the first week of treatment (11). In the present study, inositol also appeared safe; however, this study's power to detect differences in uncommon adverse events is limited by the small sample size, and infants received only a single dose. Although the higher rates of bronchopulmonary dysplasia and sepsis in the highest dose group were unexpected, have not been previously reported, and are not statistically significant, it will be important to monitor these event rates during future studies. To date, reported studies do not describe i.v. inositol supplementation for $>8 \mathrm{~d}$. 
Table 7. PK model parameter estimates for a typical infant (fixed effects)

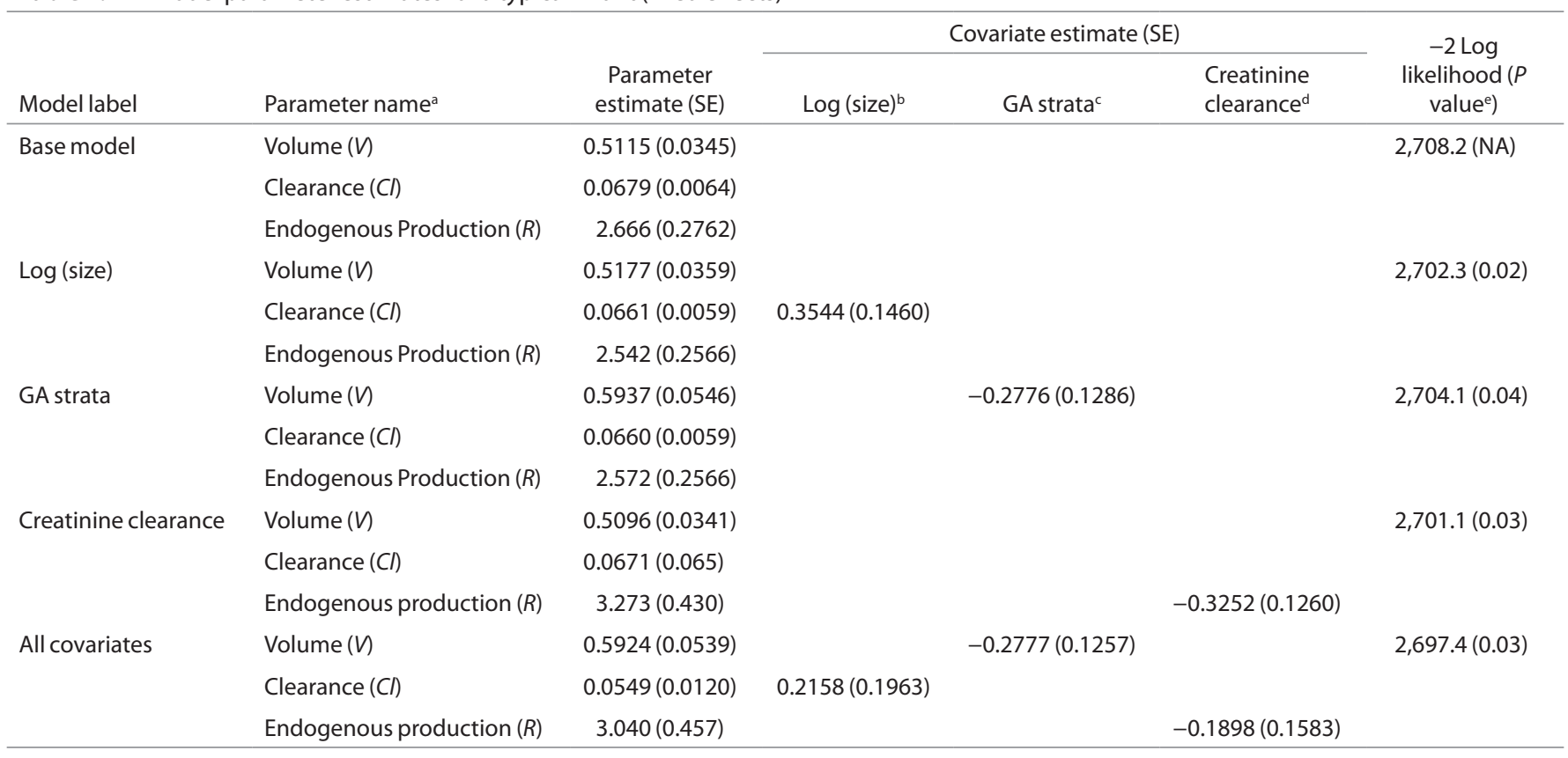

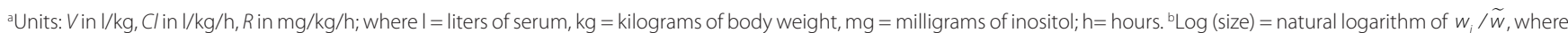
$w_{i}$ is the birth weight, in grams, for the $i$-th infant, $\widetilde{w}$ is the median birth weight of the infants in the study ( 997.5 gm). ${ }^{c} G$ estational age strata: reference cell: $23-26$ wk; comparison cell: $27-29 \mathrm{wk} .{ }^{\mathrm{d}}$ Creatinine clearance: clearance in $\mathrm{ml} / \mathrm{min}$; ${ }^{\mathrm{e}} \mathrm{P}$ value for testing the model including the covariates versus the base model without the covariates.

Hallman et al. (11) observed an apparent steady-state serum concentration after the first of $5 \mathrm{~d}$ of $80 \mathrm{mg} / \mathrm{kg} / \mathrm{d}$ dosing. The fall in serum levels in the "wash out" period in the study by Hallman et al. (11) suggested a half-life of 4-5 d, which differs substantially from our estimate $(5.22 \mathrm{~h})$ and is not explained, although fully established enteral intake of human milk in their studies may have contributed to support the serum levels despite discontinuing i.v. dosing. A PK study conducted with repeated dosing and a wider range of doses should help resolve these findings.

Brown et al. (16) found that the plasma rate of appearance of inositol in term and late-preterm infants was $121.7 \mathrm{mg} /$ $\mathrm{kg} / \mathrm{d}$, well in excess of the usual daily enteral intake from preterm formulas or human milk $(\sim 54 \mathrm{mg} / \mathrm{kg} / \mathrm{d})$. Endogenous production from glucose occurs in many tissues, and enterally received inositol is actively transported across the intestinal mucosa where it is absorbed almost completely $(17,18)$. The catabolic enzyme for inositol, myo-inositol oxidase, is localized almost exclusively to the renal cortex (19), but the activity of this enzyme is very low in the fetal and newly born renal cortex. It rises rapidly after birth as the renal blood flow redistributes from the renal medulla to the cortex. Therefore, urinary losses of intact inositol are high in both the term and preterm newborn but gradually fall to very low levels in the weeks after birth $(4,20)$. Despite these developmental physiologic mechanisms that affect inositol concentrations, serum levels remain responsive to dietary intake decreasing in both tissue and serum when diets are low in inositol and rising with supplemented diets (4).

We speculate that immature renal tubular transport at these stages of development is inadequate to reabsorb the amount of inositol filtered by the glomerulus, similar to glucose in extremely-low-birth-weight newborns. The amount of filtered inositol reaching the renal tubules over a short period of time exceeded renal tubular reabsorption so the higher dose caused a greater renal loss. This pattern of renal excretion is expected to change rapidly postnatally and could lead to reabsorption of a greater percentage of the dose and higher circulating concentrations rather than to faster clearance and shorter halflives which occurs with most drugs administered to preterm newborns during maturation. With the expected increase in the catabolic myo-inositol oxidase enzyme in the renal cortex in the weeks after birth, remaining filtered inositol will likely be converted to D-glucuronic acid, and no longer appear in the urine (19). These observations and remaining uncertainties are important to the design of future multidose efficacy trials. We plan to examine daily administration of inositol over longer periods of time. Different doses will be evaluated, and divided doses will be used in an attempt to reduce peak serum levels and therefore reduce urine losses. As we increase our understanding of how to influence serum levels, we can better test inositol's safety and potential to benefit extremely preterm infants.

\section{METHODS}

Design

A randomized, double-masked, placebo-controlled PK trial with sparse blood sampling was conducted by the National Institutes of Child Health and Human Development Neonatal Research Network. Ten of the Neonatal Research Network Centers participated and enrolled subjects between June 2006 and December 2007. Randomization was performed centrally via computer within two prespecified GA strata $\left(23^{0 / 7}-26^{6 / 7} \mathrm{wk}\right.$, and $\left.27^{0 / 7}-29^{6 / 7} \mathrm{wk}\right)$, and infants were monitored prospectively for toxicity and clinical outcomes during hospitalization. 


\section{Population}

Eligible subjects were of $23^{0 / 7}-29^{6 / 7}$ wk gestation and $\geq 600 \mathrm{~g}$ birth weight, had no major congenital anomalies, were between $12 \mathrm{~h}$ and $6 \mathrm{~d}$ of age at randomization, and had received no human milk or formula feedings since birth.

\section{Intervention}

Inositol was given as a single low $(60 \mathrm{mg} / \mathrm{kg})$ or high $(120 \mathrm{mg} / \mathrm{kg})$ dose of $5 \%$ myo-inositol (referred to as "inositol" in the remaining text) i.v. over $20 \mathrm{~min}$ in a 1:1:1 randomization with placebo delivered in one of two volumes to maintain masking (5\% glucose, United States Pharmacopeia, for i.v. administration). Drug or placebo was dispensed from the respective pharmacies in unit doses labeled as "inositol study drug," and all clinical and research personnel except the pharmacist were masked to the study group. Inositol (hexahydroxycyclohexane) is manufactured from corn or rice bran and was provided as an isotonic, pyrogen- and preservative-free, sterile $5 \%$ solution of myo-inositol in water containing $0.5 \mathrm{~g}$ sodium chloride per liter $(8.55 \mathrm{mmol} / \mathrm{l})$, with $\mathrm{pH}$ ranging between 6.5 and 7.5 .

\section{Outcome Variables}

Infants were continuously observed during the infusion by study personnel, and vital signs were recorded every $5 \mathrm{~min}$ for the first $30 \mathrm{~min}$ and thereafter at $15-30$-min intervals for $2 \mathrm{~h}$. Six prespecified clinical conditions and seven concomitant medications were recorded for $4 \mathrm{~d}$ after infusion (clincical conditions: culture-positive sepsis, patent ductus arteriosus, clinically diagnosed IVH, imaged IVH, supplemental oxygen, and mechanical ventilation; and medications: surfactant, dopamine/dobutamine, antibiotics, indomethacin as prophylaxis for IVH, indomethacin as a treatment for PDA, systemic steroids, and diuretics).

\section{Adverse Events}

Adverse events were recorded for $7 \mathrm{~d}$, and severity determined using a toxicity table modified for neonatal use from the National Cancer Institute. Baseline characteristics and demographic data as well as neonatal morbidities from birth through hospital discharge (or $120 \mathrm{~d}$ if sooner) were recorded from the medical record using the definitions of the Neonatal Research Network generic database. Bronchopulmonary dysplasia was defined as receiving oxygen at $36 \mathrm{wk}$ postmenstrual age (or at discharge if discharged before $36 \mathrm{wk}$ postmenstrual age); IVH was classified according to Papile et al's study (21); late-onset sepsis was defined as a positive culture from a normally sterile body fluid obtained after $72 \mathrm{~h}$ of age; and necrotizing enterocolitis was defined as either Modified Bell's IIA or worse not needing surgery, or requiring surgery (IIIB) (22).

\section{Blood Sampling}

Each subject contributed four blood samples (one predose plus three postdose samples) according to a sparse sampling, Pop PK design $(23,24)$. The predose sample was within $4 \mathrm{~h}$ before infusion, and the three postdose samples were distributed among nine sample windows: within $4 \mathrm{~min}$ of the end of infusion, $4 \pm 1 \mathrm{~h}, 8 \pm 1 \mathrm{~h}, 12 \pm 1 \mathrm{~h}, 24 \pm 2 \mathrm{~h}, 36 \pm 2 \mathrm{~h}$, $48 \pm 2 \mathrm{~h}, 72 \pm 2 \mathrm{~h}$, and $96 \pm 2 \mathrm{~h}$ after the start of the infusion. In addition, some scavenged serum samples from the clinical laboratories were obtained, with consent, to supplement the scheduled samples. The exact time of sampling in relation to the end of drug infusion was recorded for all samples. Blood $(200 \mu \mathrm{l})$ was collected in serum separator microtubes, refrigerated until centrifugation, up to $60 \mathrm{~h}$ after sampling, and frozen at $-70{ }^{\circ} \mathrm{C}$ to $-80^{\circ} \mathrm{C}$ until analyzed. (Stability data at room temperature for up to a week are available from the authors upon request.)

\section{Urine Collections}

Six consecutive urine collection procedures were carried out starting from 8 to $12 \mathrm{~h}$ before the infusion of study drug and continued for $96 \mathrm{~h}$ postinfusion (the second two for $12 \mathrm{~h}$ each, then three for $24 \mathrm{~h}$ each). Urine volume was determined by the change in weight of each preweighed non-gel-containing diaper with cotton balls within the given 12 - or 24 -h time period, assuming $1 \mathrm{~g}=1 \mathrm{ml}$. Urine was extracted from the diapers and cotton balls and pooled within each timed collection, and inositol and creatinine were determined on an aliquot of the pooled sample. Serum creatinine was measured at least twice during the $96 \mathrm{~h}$ by each institution's clinical laboratories.

\section{Enteral Inositol Intake}

Following drug infusion, enteral intake was permitted when the infant was considered as "ready to begin feedings" by the clinical team. Enteral intake (type and volume each day) was recorded for 4 $\mathrm{d}$ beginning with the day of study drug infusion. Samples of ingested milk were assayed for inositol to permit estimation of additional inositol intake during the sampling period.

\section{Assay}

Inositol isomers (myo-inositol, 1,5-anhydro-D-sorbitol, and D-chiroinositol) were quantified from 25 or $50 \mu$ l samples using high-performance liquid chromatography with electrochemical (pulsed amperometry) detection (method and validation documents available upon request from http://www.ttuhsc.edu/sop/research/internalgrants/CPET.aspx., Leff RD). Results of validation experiments showed the following assay performance parameters: lower limit of quantitation $1.0 \mathrm{mg} / \mathrm{l}$; coefficient of variation from low to high concentrations was $10.2-13.4 \%$ between days, and $1.9-2.3 \%$ within a day. Validated test samples included serum; plasma collected using EDTA, sodium heparin, or lithium heparin; urine extracted from any of five common nongel preterm infant diaper types with or without cotton balls; human milk and infant formulas. Serum, human milk and formulas contained only nondetectable or only barely detectable levels of the D-sorbitol and D-chiro-inositol isomers. Therefore, only myoinositol levels are reported. The concentration of inositol in formulas was $356(67) \mathrm{mg} / \mathrm{l}(\mathrm{m}( \pm \mathrm{SD}))$ and in human milk was $287(107) \mathrm{mg} / \mathrm{l}$.

\section{Statistical Analyses}

The planned sample size was at least 36 infants in each GA stratum who received study drug and completed four blood sampling procedures. Baseline characteristics and clinical outcomes for all randomized infants were analyzed by study group using $\chi^{2}$ tests, Fisher's exact tests, ANOVA, or Kruskal-Wallis tests, where appropriate.

\section{PK Analysis}

Pop-PK models were fit to the data using the nonlinear mixed-effects approach in Monolix (Monolix version 3.2. LIXOFT http://www.lixoft.com/, Paris, France). This approach accounts for the variability between infants in the model parameters, the correlation between measurements on the same infant at different occasions, and the residual unexplained variability in serum concentrations (25).

As noted, inositol is produced endogenously and is present in human milk and infant formulas (26). Hence, the Pop-PK model had to account for an endogenous serum concentration of inositol not related to treatment. Apparent endogenous inositol production was included in the Pop-PK model similarly to Hayashi (27). The final model combines apparent endogenous production with a one-compartment i.v. infusion model with linear elimination. The model for serum concentration is then

$$
C_{i}(t)=\frac{R_{i}}{C l_{i}}+\left\{\begin{array}{c}
\frac{D_{i}}{T \times C l_{i}}\left[1-e^{-\frac{C l_{i} \times t}{V_{i}}}\right] \text { if } t \leq T \\
\frac{D_{i}}{T \times C l_{i}}\left[1-e^{-\frac{C l_{i} \times T}{V_{i}}}\right]\left[e^{-\frac{C l_{i} \times(t-T)}{V_{i}}}\right] \text { if } t>T
\end{array}\right\}+\epsilon_{i t}
$$

where for the $i$-th infant, $C_{i}(t)$ is the serum concentration at time $t, R_{i}$ the apparent rate of inositol infusion due to the combination of endogenous production and feeding, $\mathrm{Cl}_{i}$ the clearance, and $V_{i}$ the apparent volume of distribution. $T$ is the duration of the infusion period and $t$ is the time after the start of the infusion, both in hours; finally, $\epsilon_{i t}$ is the residual error at time $t$. The steady-state endogenous concentration is then given by $E_{i}=R_{i} / C l_{i}$ for the ith infant, which is used to measure the combined effect of endogenous inositol production and inositol intake from enteral feeding. It was not possible to separate these two sources of inositol since enteral intake was measured as a total amount fed over a day and not the amount fed at each occasion (feedings are given eight times throughout the 24 -h day). In addition, the enteral 
intake of inositol was very low during the 4 -d study. There was a minimal enteral intake of inositol in the first $12 \mathrm{~h}$ after the i.v. dose, and a maximum of $3.6 \mathrm{mg} / \mathrm{kg}$ in the first $24 \mathrm{~h}$. Only $49 \%$ of subjects received any enteral intake in the second 24 -h period (mean intake of inositol: $1.8 \mathrm{mg} / \mathrm{kg} / \mathrm{d}$; range: $0-20$ ), and the mean intakes on days 3 and 4 were 4.5 and $5.5 \mathrm{mg} / \mathrm{kg}$, respectively. Because the calculated enteral intake of inositol from human milk or formula among those able to receive some feedings was so low during the first two study days; measured enteral intake was not included as a separate source in these models.

The between-infant variability in the Pop-PK model parameters, $R_{i}$, $C l_{i}$, and $V_{i}$ is modeled using random-effect variables $\left(u_{R}, u_{C p}\right.$ and $\left.u_{V}\right)$ that approximate the individual trajectory over time of each infant's concentration. The random effects are assumed to be normally distributed with means of 0 (zero) and variances and correlations that will be estimated. For example, the clearance for the $i$-th infant is modeled as $\mathrm{Cl}_{i}=C l \times e^{u_{C l i}}$, where $\mathrm{Cl}$ is the fixed-effect common to all infants and $u_{C l i}$ is the random effect unique to the $i$-th infant. A similar formulation is used for $R_{\mathrm{i}}$ and $V_{\mathrm{i}}$. Thus, the three model parameters are log normal. Individual specific parameter estimates were obtained as the conditional modes, or the maximum a posteriori, of the Bayes estimates of the parameters. The fixed effects, $R, C l$, and $V$, are the median values of the parameters and are called the typical values for the population from which each infant's parameters are derived. The residual error, $\epsilon_{i t}$, is assumed to be uncorrelated with the random effects and normally distributed with mean 0 (zero) and a variance that will be estimated.

The quality of fit of a Pop-PK model was judged by visual examination of plots of observed vs. individual predicted concentrations and of residuals vs. individual predicted concentrations. Nested models were compared by referencing the improvement in the objective function $\left(-2 \log\right.$ likelihood) against the $\chi^{2}$ distribution with degrees of freedom equal to the difference in the number of estimated parameters between two models. Statistical significance was assessed at the level of $P \leq 0.05$.

\section{Ethical Oversight}

The institutional review boards of each center approved the protocol, and written informed consent was obtained for each participant. An independent Data Safety Monitoring Committee approved the protocol and monitoring plan before the study began and monitored the accumulating safety data at regular intervals. The US Food and Drug Administration approved protocol (IND: 70510) was registered with ClinicalTrials.gov (NCT00349726).

\section{SUPPLEMENTARY MATERIAL}

Supplementary material is linked to the online version of the paper at http:// www.nature.com/pr

\section{ACKNOWLEDGMENTS}

We are indebted to our medical and nursing colleagues and the infants and their parents who agreed to take part in this study. Additional investigators to those listed as authors contributed to this study and are listed in the Supplementary Data online.

\section{STATEMENT OF FINANCIAL SUPPORT}

The National Institutes of Health provided grant support through the Eunice Kennedy Shriver National Institute of Child Health and Human Development's (NICHD) Neonatal Research Network and the Pediatric Pharmacology Research Units Network, with cofunding from the National Eye Institute and with support from the National Center for Research Resources, and the National Center for Advancing Translational Sciences.

The content of the publication is solely the responsibility of the authors and does not necessarily represent the official views of the National Institutes of Health. Additional participants and grant numbers are cited in the Supplementary Material online.

Disclosure: None of the authors report any commercial, proprietary, or financial interest in any of the products described in this article. Abbott Nutrition Division, Abbott Laboratories, supplied the inositol drug used in the study. $\mathrm{NICHD}$ is the sponsor of the study and holds the investigational new drug (IND) number. Portions of this study were presented at the 2010 Pediatric Academic Societies Annual Meeting, Vancouver, Canada, May 1-4, 2010.

\section{REFERENCES}

1. Michell RH. Inositol derivatives: evolution and functions. Nat Rev Mol Cell Biol 2008;9:151-61.

2. Sauer K, Cooke MP. Regulation of immune cell development through soluble inositol-1,3,4,5-tetrakisphosphate. Nat Rev Immunol 2010;10:257-71.

3. Okazaki IJ, Moss J. Characterization of glycosylphosphatidylinositiolanchored, secreted, and intracellular vertebrate mono-ADP-ribosyltransferases. Annu Rev Nutr 1999;19:485-509.

4. Holub BJ. Metabolism and function of myo-inositol and inositol phospholipids. Annu Rev Nutr 1986;6:563-97.

5. Carver JD, Stromquist CI, Benford VJ, Minervini G, Benford SA, Barness LA. Postnatal inositol levels in preterm infants. J Perinatol 1997;17:389-92.

6. Bromberger P, Hallman M. Myoinositol in small preterm infants: relationship between intake and serum concentration. J Pediatr Gastroenterol Nutr 1986;5:455-8.

7. Brusati V, Jóźwik M, Jóźwik M, et al. Fetal and maternal non-glucose carbohydrates and polyols concentrations in normal human pregnancies at term. Pediatr Res 2005;58:700-4.

8. Hallman $M$, Järvenpää AL, Pohjavuori M. Respiratory distress syndrome and inositol supplementation in preterm infants. Arch Dis Child 1986;61:1076-83.

9. Hallman M, Arjomaa P, Hoppu K. Inositol supplementation in respiratory distress syndrome: relationship between serum concentration, renal excretion, and lung effluent phospholipids. J Pediatr 1987;110:604-10.

10. Hallman M, Pohjavuori M, Bry K. Inositol supplementation in respiratory distress syndrome. Lung 1990;168:Suppl:877-82.

11. Hallman M, Bry K, Hoppu K, Lappi M, Pohjavuori M. Inositol supplementation in premature infants with respiratory distress syndrome. N Engl J Med 1992;326:1233-9.

12. Friedman CA, McVey J, Borne MJ, et al. Relationship between serum inositol concentration and development of retinopathy of prematurity: a prospective study. J Pediatr Ophthalmol Strabismus 2000;37:79-86.

13. Howlett A, Ohlsson A, Plakkal N. Inositol for respiratory distress syndrome in preterm infants. Cochrane Database Syst Rev 2012;3:CD000366.

14. Stoll BJ, Hansen NI, Bell EF, et al.; Eunice Kennedy Shriver National Institute of Child Health and Human Development Neonatal Research Network. Neonatal outcomes of extremely preterm infants from the NICHD Neonatal Research Network. Pediatrics 2010;126:443-56.

15. Meibohm B, Läer S, Panetta JC, Barrett JS. Population pharmacokinetic studies in pediatrics: issues in design and analysis. AAPS J 2005;7:E475-87.

16. Brown LD, Cheung A, Harwood JE, Battaglia FC. Inositol and mannose utilization rates in term and late-preterm infants exceed nutritional intakes. J Nutr 2009;139:1648-52.

17. Caspary WF, Crane RK. Active transport of myo-inositol and its relation to the sugar transport system in hamster small intestine. Biochim Biophys Acta 1970;203:308-16.

18. Nahapetian A, Young VR. Metabolism of 14C-phytate in rats: effect of low and high dietary calcium intakes. J Nutr 1980;110:1458-72.

19. Troyer DA, Schwertz DW, Kreisberg JI, Venkatachalam MA. Inositol phospholipid metabolism in the kidney. Annu Rev Physiol 1986;48:51-71.

20. Lewin LM, Melmed S, Passwell JH, et al. Myoinositol in human neonates: serum concentrations and renal handling. Pediatr Res 1978;12:3-6.

21. Papile LA, Burstein J, Burstein R, Koffler H. Incidence and evolution of subependymal and intraventricular hemorrhage: a study of infants with birth weights less than 1,500 gm. J Pediatr 1978;92:529-34.

22. Walsh MC, Kliegman RM. Necrotizing enterocolitis: treatment based on staging criteria. Pediatr Clin North Am 1986;33:179-201.

23. Duffull S, Waterhouse T, Eccleston J. Some considerations on the design of population pharmacokinetic studies. J Pharmacokinet Pharmacodyn 2005;32:441-57.

24. Mahmood I, Duan J. Population pharmacokinetics with a very small sample size. Drug Metabol Drug Interact 2009;24:259-74.

25. Bertrand J, Comets E, Mentré F. Comparison of model-based tests and selection strategies to detect genetic polymorphisms influencing pharmacokinetic parameters. J Biopharm Stat 2008;18:1084-102.

26. Holub BJ. The nutritional importance of inositol and the phosphoinositides. N Engl J Med 1992;326:1285-7.

27. Hayashi N, Kinoshita H, Yukawa E, Higuchi S. Pharmacokinetic analysis of subcutaneous erythropoietin administration with nonlinear mixed effect model including endogenous production. $\mathrm{Br} \mathrm{J}$ Clin Pharmacol 1998;46:11-9. 